\title{
Participation of citric acid and isocitric acid in the diurnal cycle of carboxylation and decarboxylation in the common ice plant
}

\author{
K. Gawronska $\cdot$ E. Niewiadomska
}

Received: 14 October 2014/Revised: 8 January 2015/Accepted: 10 February 2015/Published online: 24 February 2015

(C) The Author(s) 2015. This article is published with open access at Springerlink.com

\begin{abstract}
In this paper we analyzed changes in the concentration of the three carboxylic acids (malic acid, citric acid and isocitric acid) during the salinity-induced $\mathrm{C}_{3}-$ CAM shift in Mesembryanthemum crystallinum. We documented that a nocturnal accumulation of citrate preceded that of malate, and that the CAM-dependent increase in citric acid was about 100-times higher than that of malic acid. The induction of CAM was accompanied by an increased activity of cytosolic NADP-dependent isocitrate dehydrogenase (NADP-ICDH, E.C 1.1.1.42) and by decreased activities of mitochondrial enzymes: fumarase (E.C 4.2.1.2) and NAD-dependent ICDH (E.C 1.1.1.41). Moreover, the activity of citrate synthase (E.C 2.3.3.1) was increased during the nocturnal phase of CAM. Altogether, obtained data suggest that some part of the product of a primary carboxylation (oxaloacetic acid) may pass through the mitochondria at night for reduction and, in form of citrate and isocitrate, may leave the mitochondria to support a daytime decarboxylation.
\end{abstract}

Keywords Citrate $\cdot$ Isocitrate $\cdot$ Mesembryanthemum crystallinum $\cdot$ TCA

Communicated by L. A. Kleczkowski.

K. Gawronska ( $\square)$

Institute of Biology, Pedagogical University, Podchorążych 2,

30-084 Krakow, Poland

e-mail: katgaw@up.krakow.pl

E. Niewiadomska

Institute of Plant Physiology, Polish Academy of Sciences,

Niezapominajek 21, 30-239 Krakow, Poland

\author{
Abbreviations \\ 2-OG 2-Oxoglutarate \\ CAM Crassulacean acid metabolism \\ CICs Citrate carriers \\ CoA Co-enzyme A \\ CS Citrate synthase \\ DICs Dicarboxylate carriers \\ DTNB 5,5'-Dithiobis-(2-nitrobenzoic acid) \\ DTT Dithiotreitol \\ GOGAT Glutamine oxoglutarate aminotransferase \\ ICDH Isocitrate dehydrogenase \\ HEPES 4-(2-Hydroxyethyl)-piperazine-1-ethansulfonic \\ acid \\ MA Malic acid \\ $\mathrm{MDH} \quad$ Malate dehydrogenase \\ ME Malic enzyme \\ OAA Oxaloacetic acid \\ PEP Phosphoenolpyruvate \\ ROS Reactive oxygen species \\ TCA Tricarboxylic acid cycle
}

\section{Introduction}

A characteristic feature of crassulacean acid metabolism (CAM) is the temporal separation of the primary and secondary carboxylation. The initial fixation of atmospheric carbon dioxide takes place during the night and it is catalyzed by phosphoenolpyruvate carboxylase (PEPC). This leads to the formation of malic acid (MA) which is stored in the vacuole. During the day, MA is released from vacuole and decarboxylated to deliver $\mathrm{CO}_{2}$ for the Calvin cycle (for reviews see Osmond 1978; Cushman and Bohnert 1999). Decarboxylation of $\mathrm{CO}_{2}$ from the primary product is catalyzed by NADP-dependent malic enzyme 
(NADP-ME), NAD-dependent malic enzyme (NAD-ME) or phosphoenolpyruvate carboxylase kinase (PEPCK). The first two reactions are coupled with the production of reducing power in the cytosol and mitochondria, respectively. Fluxes of organic acids between cell compartments, and their processing, affect the primary metabolic pathways of the mesophyll cell, such as glycolysis, gluconeogenesis, mitochondrial respiration, as well as redox homeostasis.

The first product of the nocturnal $\mathrm{CO}_{2}$ fixation is oxaloacetic acid (OAA), which is then reduced to MA. However, the exact way of this reduction has not been fully established. In the CAM inducible $M$. crystallinum, a reduction of OAA to MA during the night is thought to be catalyzed primarily by a cytosolic NAD-dependent malate dehydrogenase (Holtum and Winter 1982; Winter et al. 1982). Another possibility has been pointed out for the obligate CAM plant Kalanchöe tubiflora. When this plants were fed with ${ }^{13} \mathrm{CO}_{2}$, at the end of the night the ratio of MA molecules with labeled carbon atom in position 4-C (the result of the PEP carboxylase activity) to MA molecules with ${ }^{13} \mathrm{CO}_{2}$ in position $1-\mathrm{C}$ (the result of the fumarase activity) was 2:1 (Osmond et al. 1988; Kalt et al. 1990). This indicated that a significant proportion of accumulated MA passed through mitochondria during the night, thus mitochondrial metabolism may participate in the reduction of OAA. As the mitochondrial metabolism is an oxidative machinery, hence, to retain some reduced intermediates, an export of carboxylic acids may occur.

Previous studies have shown that in addition to malate, citrate may also play an important role in CAM (Lüttge 1988; Franco et al. 1992; Borland et al. 1996; Miszalski et al. 2007). Nevertheless, the role of citrate in CAM plants has not been ultimately defined. It was hypothesized, that the nocturnal accumulation of citrate in comparison to malate may be energetically more favorable (Lüttge 1988; Winter and Smith 1996). The accumulation of citrate may also play a significant role during the light phase. The essence of daytime decarboxylation of organic acids is to provide a big pool of $\mathrm{CO}_{2}$, which allows for the intensive photosynthesis. Maxwell et al. (1994) suggested that the simultaneous decarboxylation of citrate and malate may increase the intracellular pool of $\mathrm{CO}_{2}$ in conditions of limited supply of atmospheric $\mathrm{CO}_{2}$. The release of $\mathrm{CO}_{2}$ from citrate is possible after its isomerization to isocitrate. Then, isocitrate may be subjected to the oxidative decarboxylation catalyzed by isocitrate dehydrogenase (ICDH). Citrate and isocitrate may also play a role in stress defense, when increased production of NADPH is necessary for functioning of the ascorbate-glutathione cycle (HaagKerwer et al. 1996).

In the facultative CAM plant $M$. crystallinum, MA was the main carboxylic acid accumulated during the nocturnal phase. However, an increased concentration of citrate was also detected during the stress-induced $\mathrm{C}_{3}-\mathrm{CAM}$ shift (Herppich et al. 1995). The aim of this study was to determine whether the mitochondrial metabolism might be involved in the nocturnal reduction of OAA. Second goal was to verify if intermediates of TCA (citric acid and isocitric acid) can serve as a source of $\mathrm{CO}_{2}$ consumed during the day.

\section{Materials and methods}

\section{Plant material}

Mesembryanthemum crystallinum L. plants were grown from seeds in the soil culture under irrigation with tap water. Plants were cultivated in the phytotron chamber at temperatures of $25 / 17^{\circ} \mathrm{C}$ day/night, $12 \mathrm{~h}$ photoperiod, irradiance of $250 \mu \mathrm{mol} \mathrm{m} \mathrm{m}^{-2} \mathrm{~s}^{-1}$ and $\mathrm{RH} \sim 50 \%$. After the appearance of the third leaf pair, approximately 4 weeks after sowing, plants were divided into the two sets: the first set was irrigated with water (control), the second was irrigated with $0.4 \mathrm{M} \mathrm{NaCl}$. Diurnal time-course experiments were performed with plants irrigated for 12 days with salt solution or tap water.

\section{Determinations of malate, citrate and isocitrate levels}

For determination of carboxylic acids leaves were collected at the beginning of the light phase and about $2 \mathrm{~h}$ before the beginning of the dark period. The leaf cell sap was centrifuged for $5 \mathrm{~min}$ at $12,000 \mathrm{~g}$ and the supernatant was used for further determinations. Prior to the measurements of malate, citrate and isocitrate, samples of collected cell sap were heated at $100{ }^{\circ} \mathrm{C}$ for $3 \mathrm{~min}$ to inactivate the enzymes. Malate and citrate were measured according to Miszalski et al. (2007). Isocitrate was measured according to Chen et al. (2002).

\section{Enzyme activities}

For measurements of citrate synthase (CS, E.C 2.3.3.1) and fumarase (E.C 4.2.1.2) activities leaf tissue (1 g) was homogenized on ice in $2.5 \mathrm{~mL} \mathrm{0.1} \mathrm{M} \mathrm{HEPES-KOH} \mathrm{pH} \mathrm{8.0,}$ containing $2 \mathrm{mM}$ DTT and $2 \mathrm{mM} \mathrm{MnCl}_{2}$. Homogenates were centrifuged at $12,000 \mathrm{~g}$ for $2 \mathrm{~min}$ at $4{ }^{\circ} \mathrm{C}$ and the supernatant was immediately used for measurements of enzyme activity. CS activity was determined according to Srere (1967). The reaction medium composed of $100 \mathrm{mM}$ Tris$\mathrm{HCl} \mathrm{pH} 8.0$, containing $0.1 \%(\mathrm{w} / \mathrm{v})$ Triton $\mathrm{X}-100,1 \mathrm{mM}$ acetyl-CoA and $10 \mathrm{mM}$ DTNB. The reaction was started with addition of $1 \mathrm{mM}$ OAA and was monitored at $412 \mathrm{~nm}$ for $3 \mathrm{~min}$. Extinction coefficient of DTNB of 
$14.15 \mathrm{mM}^{-1} \mathrm{~cm}^{-1}$ was used for calculations. Fumarase activity was determined according to Racker (1950) by monitoring the formation of fumaric acid at $240 \mathrm{~nm}$. The reaction was performed in $50 \mathrm{mM}$ Tricine $\mathrm{pH} 8.0$, containing $0.02 \%(\mathrm{w} / \mathrm{v})$ Triton X-100 and $60 \mathrm{mM} \mathrm{L-malate.} \mathrm{Extinction}$ coefficient of fumarate of $2.44 \mathrm{mM}^{-1} \mathrm{~cm}^{-1}$ was used.

The activity of NADP- and NAD-dependent isocitrate dehydrogenases (NADP-ICDH, E.C 1.1.1.42 and NADICDH, E.C 1.1.1.41) was determined according to Popova et al. (2002). For extraction of NADP-ICDH, $1 \mathrm{~g}$ of plant material was homogenized in $100 \mathrm{mM}$ Tris- $\mathrm{HCl} \mathrm{pH} 8.0$, containing $1.5 \mathrm{mM}$ isocitrate, $2 \mathrm{mM} \mathrm{MnCl}_{2}$. For extraction of NAD-ICDH, $1 \mathrm{~g}$ of plant material was homogenized in $50 \mathrm{mM}$ HEPES pH 7.6, containing $20 \%$ glycerol, $0.1 \%$ Tween, $0.1 \mathrm{mM} \mathrm{NaHCO}_{3}$ and $5 \mathrm{mM}$ DTT. After centrifugation at $10,000 \mathrm{~g}$ for $15 \mathrm{~min}$ the supernatant was collected and the reduction of $\mathrm{NADP}^{+}$and $\mathrm{NAD}^{+}$was monitored at $340 \mathrm{~nm}$ at $25^{\circ} \mathrm{C}$ in $100 \mathrm{mM}$ Tris- $\mathrm{HCl} \mathrm{pH}$ 8.0 , containing $1.5 \mathrm{mM}$ isocitrate, $2 \mathrm{mM} \mathrm{MnCl}_{2}, 0.5 \mathrm{mM}$ $\mathrm{NADP}^{+}$or in $50 \mathrm{mM}$ HEPES $\mathrm{pH} 7.6$, containing $1 \mathrm{mM}$ isocitrate, $1 \mathrm{mM} \mathrm{MnSO} 4,0.8 \mathrm{mM} \mathrm{NAD}^{+}$, respectively. Extinction coefficient of NADH and NADPH of $6.22 \mathrm{mM}^{-1} \mathrm{~cm}^{-1}$ was used for calculations.

The level of soluble proteins was determined by the method of Bradford (1976) using albumin bovine as standard.

\section{Statistics}

The significant differences between the means were assessed by Student's $t$ test.

\section{Results}

Treatment of $M$. crystallinum plants with $0.4 \mathrm{M} \mathrm{NaCl}$ led to the typical CAM diurnal rhythm of acidity, characterized by the increased concentration of MA during the night and decreased during the day. Concentration of MA was increased up to $27.5 \mathrm{mM}$ in salt-treated plants at the end of the night (Fig. 1a). Whereas, in control plants, a nocturnal malate concentration was more or less constant during the course of the experiment, reaching the maximal value of $2.6 \mathrm{mM}$. In salt-treated plants an increase in nocturnal accumulation of citrate was detected from day 3 of the experiment (Fig. 1b). The highest nocturnal accumulation of citric acid (29.4 mM) occurs on day 14 of the salt treatment and was approximately 200 times higher compared to the control. After the onset of salt stress a nocturnal accumulation of isocitric acid was detected (Fig. 1c). Accumulation of isocitric acid during the night in CAM plants was about ten times lower in comparison to citric acid. Whereas, the absence of salinity stress concentration of isocitric acid remained low during the whole time-

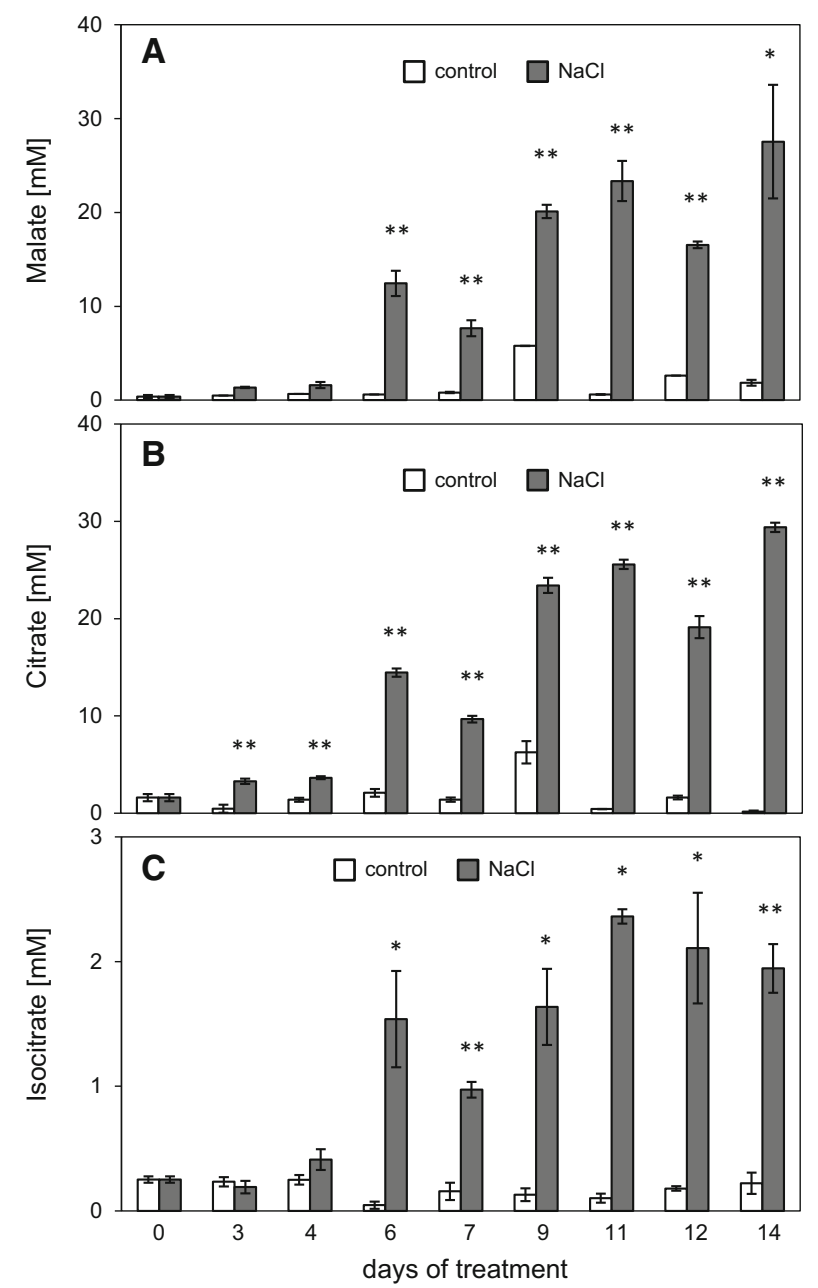

Fig. 1 The level of malate (a), citrate (b) and isocitrate (c) in the cell sap from $M$. crystallinum leaves collected at the beginning of photoperiod from: controls and treated with $0.4 \mathrm{M} \mathrm{NaCl}$. Data represent mean values $\pm \mathrm{SD}(n \geq 4)$. Asterisks above the bars indicate the level of significance of differences from the controls according to Student's $t$ test: $P<0.05(*), P<0.01(* *)$

course of experiment. A significant difference between the morning and evening concentrations of malate and isocitrate ( $\Delta$ malate and $\Delta$ isocitrate) appeared at day 6 of salinity treatment. Whereas, significant differences in $\Delta$ citrate started from day 3 of salinity treatment (Table 1).

To get the insight into the capacity of TCA cycle to metabolize OAA, we followed the activity of citrate synthase. Similar activities of $\mathrm{CS}$ were detected in $\mathrm{C}_{3}$ and salinitytreated plants (at midday) during the course of the experiment (Fig. 2). However, when the activity of this enzyme was analyzed in a diurnal course, an increased activity of CS was documented at the end of light period and during the dark period, in the salinity-treated plants (Fig. 3a).

Salt treatment led to a decrease in fumarase activity during the entire diurnal cycle, as demonstrated in Fig. $3 b$. This enzyme represents the later step of TCA cycle, in comparison to CS. In control plants the activity of 
Table 1 Diurnal changes in malate, citrate and isocitrate concentration in sap cell from leaves from $M$. crystallinum plants: controls and treated with $0.4 \mathrm{M} \mathrm{NaCl}$

\begin{tabular}{|c|c|c|c|c|}
\hline & \multicolumn{4}{|c|}{ Days of treatment } \\
\hline & 3 & 6 & 9 & 12 \\
\hline \multicolumn{5}{|l|}{ Malate } \\
\hline Control & $-2.14 \pm 0.30$ & $-0.44 \pm 0.38$ & $-0.57 \pm 0.29$ & $0.07 \pm 0.66$ \\
\hline $\mathrm{NaCl}$ & $-2.075 \pm 0.82$ & $-0.6 \pm 1.36$ & $7.75 \pm 1.28$ & $14.07 \pm 2.34$ \\
\hline \multicolumn{5}{|l|}{ Citrate } \\
\hline Control & $0.14 \pm 0.25$ & $1.25 \pm 0.54$ & $-0.39 \pm 1.36$ & $0.89 \pm 0.35$ \\
\hline $\mathrm{NaCl}$ & $1.44 \pm 0.61$ & $2.74 \pm 1.08$ & $8.95 \pm 1.14$ & $10.09 \pm 0.75$ \\
\hline \multicolumn{5}{|l|}{ Isocitrate } \\
\hline Control & $-0.01 \pm 0.14$ & $-0.09 \pm 0.04$ & $-0.02 \pm 0.33$ & $0.03 \pm 0.03$ \\
\hline $\mathrm{NaCl}$ & $-0.04 \pm 0.14$ & $0.02 \pm 0.41$ & $0.65 \pm 0.33$ & $0.56 \pm 0.25$ \\
\hline
\end{tabular}

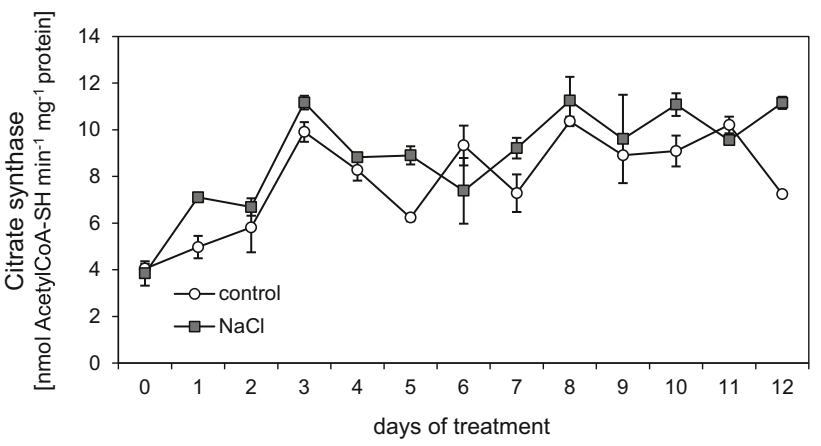

Fig. 2 The activity of CS in extracts of soluble proteins from leaves from $M$. crystallinum plants: controls and treated with $0.4 \mathrm{M} \mathrm{NaCl}$. Data represent mean values $\pm \mathrm{SD}(n=3)$

fumarase was about $50 \mathrm{nmol}$ fumarate $\mathrm{min}^{-1} \mathrm{mg}^{-1}$ protein, while in CAM plants the maximal activity of this enzyme was decreased by about $1 / 3$.

In control plants, a slight increase was noted in the activity of NAD-dependent isocitrate dehydrogenase which was slightly increasing during the experiment (Fig. 4a). Whereas, in salt-treated plants the activity of NAD-ICDH decreased significantly, in comparison to control plants, starting from day 6 . The opposite changes were detected for NADP-ICDH. The activity of NADP-ICDH was decreasing during the time of experiment in control plants, whereas, in salt-treated plants the activity of this enzyme was increasing (Fig. 4b). Significant differences in NADP-ICDH activity between the controls in salt-treated plants started from day 5. The highest activity of NADP-ICDH amounted to

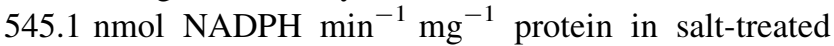
plants, while the highest activity of $197.5 \mathrm{nmol} \mathrm{NADPH}$ $\mathrm{min}^{-1} \mathrm{mg}^{-1}$ protein was measured in the controls.

\section{Discussion}

In this paper we documented that the induction of CAM in $M$. crystallinum, manifested by the appearance of $\Delta$ malate,
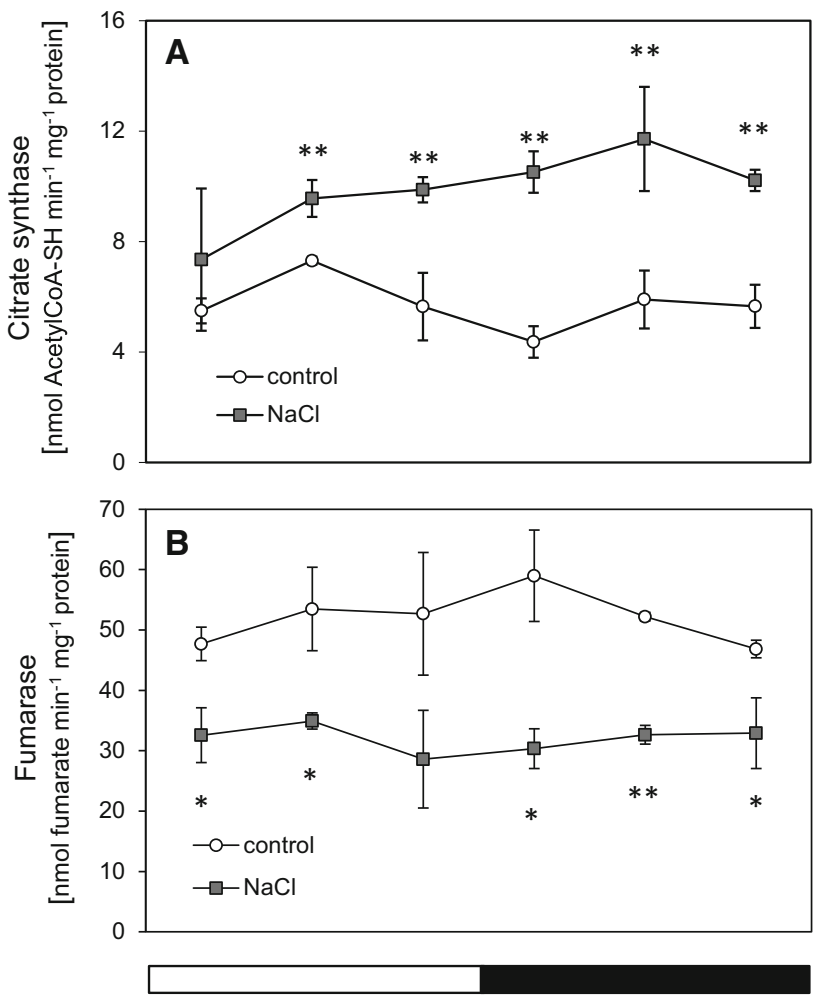

Fig. 3 Daily time-courses of the activity of CS (a) and fumarase (b) in extracts of soluble proteins from leaves from M. crystallinum plants: controls and treated with $0.4 \mathrm{M} \mathrm{NaCl}$. Data represent mean values $\pm \mathrm{SD}(n \geq 4)$. Asterisks above the bars indicate the level of significance of differences from the controls according to Student's $t$ test: $P<0.05(*), P<0.01(* *)$

is associated by the appearance of $\Delta$ citrate and $\Delta$ isocitrate. Moreover, a nocturnal accumulation of citrate preceded that of MA. CAM-dependent accumulation of citric acid is in agreement with the earlier results obtained with M. crystallinum (Herppich et al. 1995); Clusia (Franco et al. 1992; Miszalski et al. 2007; Kornas et al. 2009) and Aptenia cordifolia (Peckmann and Herppich 1998). Also, earlier accumulation of citrate than malate during the 

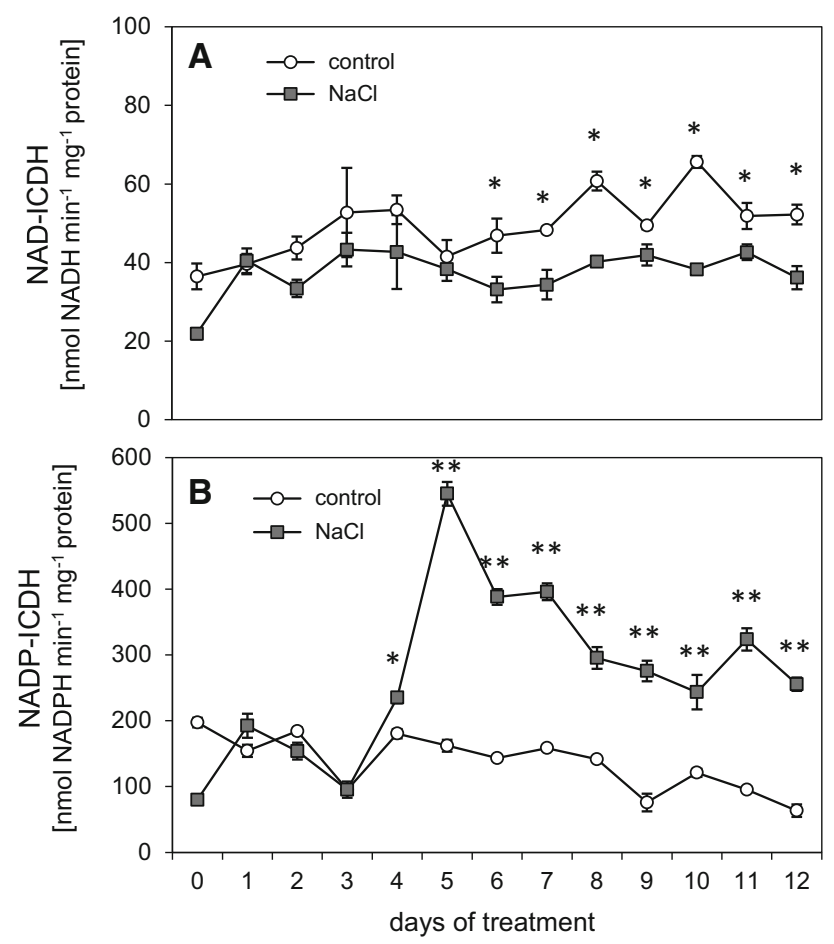

Fig. 4 The activity of NAD-ICDH (a) and NADP-ICDH (b) in extracts of soluble proteins from leaves from $M$. crystallinum plants: controls and treated with $0.4 \mathrm{M} \mathrm{NaCl}$. Data represent mean values $\pm \mathrm{SD}(n=3)$. Asterisks above the bars indicate the level of significance of differences from the controls according to Student's $t$ test: $P<0.05(*), P<0.01(* *)$

induction of CAM was evidenced before by Herppich et al. (1995). An increased isocitrate level was detected so far in leaves of obligate CAM species Kalanchöe daigremontiana and Tillandsia pohliana, and $\mathrm{C}_{3} / \mathrm{CAM}$ intermediate Sedum telephium (Kenyon et al. 1985; Chen et al. 2002; Freschi et al. 2010). However, to our knowledge this is the first report on the nocturnal accumulation of isocitrate in response of salt stress in $M$. crystallinum.

It is supposed that at the early stage of CAM induction in $M$. crystallinum the accumulation of malate is limited by a low activity of cytosolic NAD-MDH, an enzyme necessary for the nocturnal OAA reduction. As shown by Holtum and Winter (1982), this enzyme reaches its full activity after about 12 days of salinity treatment. This is also manifested by a strong up-regulation of $M d h 2$ transcripts (Cushman et al. 2008). It stays, however, unresolved what is the main source of reducing power for this reaction during the nocturnal phase. In regard to the energetics of $\mathrm{CAM}$, it has been suggested that a nocturnal formation of citrate and isocitrate is more advantageous in comparison to MA (Lüttge 1988; Winter and Smith 1996, Chen et al. 2002).

Since both citric and isocitric acids are intermediates of TCA cycle, we hypothesized that a functional redirection of this cycle may take place along with the induction of CAM. Both citrate and isocitrate originate from the synthesis of 6-carbon skeletons mediated by citrate synthase. Therefore, the activity of this enzyme was monitored during the induction of CAM. Indeed, an increased activity of this enzyme was found in the second half of photoperiod, and more pronounced at night. This pattern is in agreement with the data of Neuhaus and Schulte (1996), who documented an increased activity of CS in M. crystallinum CAM plants at the beginning of the dark period.

Up-regulation of CS may explain increased levels of both above-mentioned carboxylic acids, as long as a decreased capacity of further steps of TCA cycle does occur. This hypothesis is supported by lowering of fumarase activity after the salinity-induced $\mathrm{C}_{3}-\mathrm{CAM}$ shift. Such an effect is in agreement with the earlier data obtained with $M$. crystallinum (Miszalski et al. 2001; Niewiadomska and Borland 2008). It is likely that TCA cycle is disturbed by oxidative stress, as an enhanced generation of ROS in mitochondria of $M$. crystallinum was found as an early response to high salinity (Miszalski et al. 1998). One of the first targets of oxidative stress in mitochondria, is aconitase, due to its highly sensitive $[4 \mathrm{Fe}-4 \mathrm{~S}]^{2+}$ centers (Gardner 2002). An increased export of citrate and isocitrate from mitochondria is supported by the salinity-dependent induction of the two dicarboxylate carriers (DICs) revealed by Cushman et al. (2008). DICs exchange dicarboxylates, such as malate, succinate, and malonate, for inorganic phosphate, sulfate or thiosulphate (Palmieri et al. 2008). Additionally, transport of carboxylic acids through the inner mitochondrial membrane may also be mediated by a citrate carries, CICs (Picault et al. 2004). CICs, also known as tricarboxylate carriers, exchange a dibasic form of tricarboxylic acids (citrate, isocitrate, and cis-aconitate) for another tricarboxylic acids, dicarboxylic acids (i.e., malate or succinate) or PEP (Gnoni et al. 2009). As concluded by Wiskich and Dry (1985), export of citrate is more probable than of isocitrate, due to the aconitase equilibrium. A non-cyclic mode of TCA cycle, associated with the export of citrate to the cytosol and vacuole, has been predicted before for $\mathrm{C}_{3}$ plants on basis of the isotopic labeling experiments made on rape leaves (Gauthier et al. 2010; Sweetlove et al. 2010; Cheung et al. 2014). Such a rescue of citrate from TCA cycle might be a strategy to conserve the net carbon gain.

Later on, during the day citrate was supposed to be metabolized by a cytosolic aconitase and isocitrate dehydrogenase, as proposed in a model developed by Cheung et al. (2014). To get an insight into a possible daytime decarboxylation of $6 \mathrm{C}$ carboxylic acids we tested the activities of the NAD-dependent and NADP-dependent forms of isocitrate dehydrogenase. The NAD-depend enzyme is located exclusively in the mitochondrial matrix. While, 
Fig. 5 A schematic presentation of metabolic flux involving a nocturnal production of citrate and a daytime citrate decarboxylation in the cytosol. Left part dark period, right part light period. CHL chloroplast, CYT cytosol, MIT mitochondrion, VAC vacuole, Citr citrate, Isocitr isocitrate, $M A$ malate, $O A A$ oxaloacetate, $2-O G$

2-oxoglutarate, $P E P$ phosphoenolpyruvate, $P y r$ pyruvate, TCA tricarboxylic acid. Numbers represent enzymes involved in the flux: 1 PEPC, 2 NAD-MDH, 3 CS, 4 NADP-ICDH, 5 NADP-ME, 6 NAD-ME

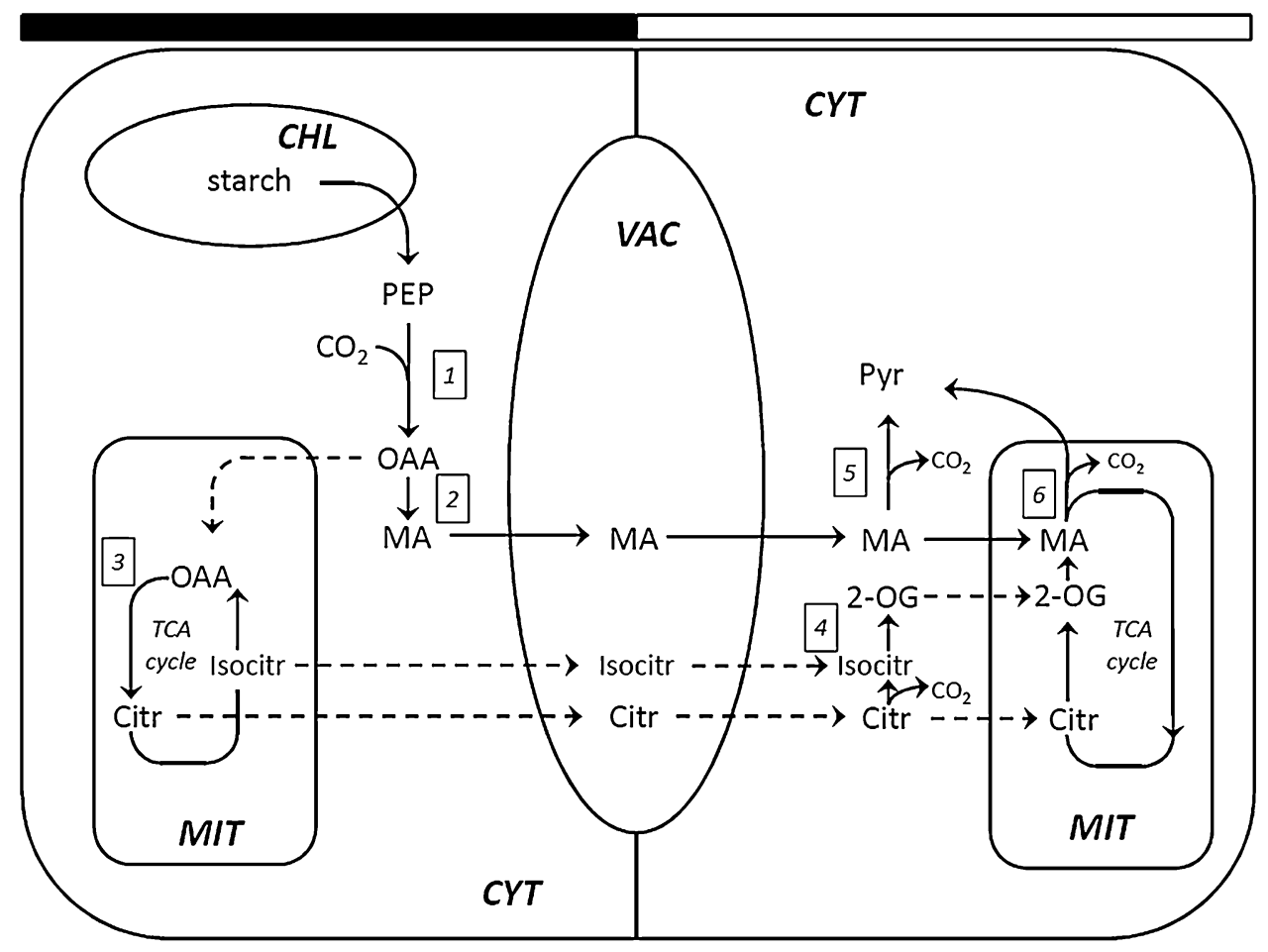

NADP-ICDH is represented in higher plants by different isoenzymes located in the cytosol, chloroplast, and mitochondria, however, a majority of its activity (90-100\%) corresponds to the cytosolic form (Chen and Gadal 1990; Gálvez et al. 1994; Gallardo et al. 1995). A substantial decrease has been documented in activity of the mitochondrial form (NAD-ICDH), in parallel to an increased activity of the cytosolic form (NADP-ICDH). Decreased NAD-ICDH activity may indicate a lower intensity of TCA cycle, in agreement with changes in fumarase activity discussed above. Whereas, an activation of the cytosolic NADP-ICDH in $M$. crystallinum due to salinity treatment is in agreement with the results obtained by Popova et al. (2002). Oxidative decarboxylation of isocitrate mediated by ICDH may be associated with the anti-oxidative defense. As suggested for the animal and plants tissues, its activation under stress might be associated with enhanced need for NADPH for restoration of reduced forms of glutathione and ascorbic acids during the $\mathrm{H}_{2} \mathrm{O}_{2}$ scavenging cycle (Leterrier et al. 2007).

The reaction catalyzed by cytosolic ICDH, aside of $\mathrm{CO}_{2}$ and reducing power, delivers 2 -oxoglutarate (2-OG). This compound may be used by a glutamine oxoglutarate aminotransferase (GOGAT) for the production of glutamic acid. A cooperation of cytosolic ICDH and GOGAT thus links the metabolism of $\mathrm{C}$ and $\mathrm{N}$. Hence, an activation of ICDH may also suggest an increased production of amino acids. However, in M. crystallinum a decreased expression and activity of GOGAT was documented after the salinity treatment (Popova et al. 2002). Assimilation of $\mathrm{N}$ is also dependent of the reducing power from photosystem I due to the ferredoxin-dependent activity of nitrite reductase. In this respect, a strongly reduced pool of electron acceptors from PSI was found in $M$. crystallinum after the salinity treatment (Niewiadomska et al. 2011). Collectively, these data suggest a decreased capacity for $\mathrm{N}$ assimilation after the salinity-induced $\mathrm{C}_{3}-\mathrm{CAM}$ shift. In this situation 2-OG released during isocitrate decarboxylation may be metabolized via TCA cycle.

In conclusion, we postulate here that a salinity-dependent increase in the nocturnal accumulation of citrate and isocitrate, followed by their daytime release and decarboxylation in the cytosol, supply $\mathrm{CO}_{2}$ during the photosynthesis behind closed stomata. A diel flux of citrate and isocitrate during development of CAM in M. crystallinum plants is presented on the scheme (Fig. 5).

Author contribution statement KG: performing the experiments and writing of the manuscript. EN: planning of the analysis and correcting of the manuscript.

Acknowledgments This work was supported by Polish National Science Centre project (2011/03/B/NZ9/01619, E.N.).

Open Access This article is distributed under the terms of the Creative Commons Attribution License which permits any use, distribution, and reproduction in any medium, provided the original author(s) and the source are credited. 


\section{References}

Borland AM, Griffiths H, Maxwell C, Fordham MC, Broadmeadow MSJ (1996) CAM induction in Clusia minor L. during the transition from wet to dry season in Trinidad: the role of organic acid speciation and decarboxylation. Plant Cell Environ 19:655-664

Bradford MM (1976) A rapid and sensitive method for quantification of microgram quantities of protein utilizing the principle of protein-dye binding. Anal Biochem 72:248-254

Chen RD, Gadal P (1990) Structure, functions and regulation of NAD and NADP-dependent isocitrate dehydrogenases in higher plants and in other organisms. Plant Physiol Biochem 28:411-427

Chen LS, Lin Q, Nose A (2002) A comparative study on diurnal changes in metabolite levels in the leaves of three crassulacean acid metabolism (CAM) species, Ananas comosus, Kalanchö̈ daigremontiana and K. pinnata. J Exp Bot 53:341-350

Cheung CY, Poolman MG, Fell DA, Ratcliffe RG, Sweetlove LJ (2014) A diel flux balance model captures interactions between light and dark metabolism during day-night cycles in $\mathrm{C}_{3}$ and crassulacean acid metabolism leaves. Plant Physiol 165(2):917-929

Cushman JC, Bohnert H (1999) Crassulacean acid metabolism: molecular genetics. Annu Rev Plant Physiol Plant Mol Biol 50:305-332

Cushman JC, Tillett RL, Wood JA, Branco JM, Schlauch KA (2008) Large-scale mRNA expression profiling in the common ice plant, Mesembryanthemum crystallinum, performing C3 photosynthesis and crassulacean acid metabolism (CAM). J Exp Bot 59:1875-1894

Franco AC, Ball E, Lüttge U (1992) Differential effects of drought and light levels on accumulation of citric and malic acids during CAM in Clusia. Plant Cell Environ 15:821-829

Freschi L, Rodrigues MA, Tiné MAS, Mercier H (2010) Correlation between citric acid and nitrate metabolisms during CAM cycle in the atmospheric bromeliad Tillandsia pohliana. J Plant Physiol 167:1577-1583

Gallardo F, Gálvez S, Gadal P, Cánovas FM (1995) Changes in $\mathrm{NADP}^{+}$-linked isocitrate dehydrogenase during tomato fruit ripening. Characterization of the predominant cytosolic enzyme from green and ripe pericarp. Planta 196:148-154

Gálvez S, Bismuth E, Sarda C, Gadal P (1994) Purification and characterization of chloroplastic NADP-isocitrate dehydrogenase from mixotrophic tobacco cells. Plant Physiol 105:593-600

Gardner PR (2002) Aconitase: sensitive target and measure of superoxide. Methods Enzymol 349:9-23

Gauthier PPG, Bligny R, Gout E, Mahé A, Nogués S, Hodges M, Tcherkez GGB (2010) In folio isotopic tracing demonstrates that nitrogen assimilation into glutamate is mostly independent from current $\mathrm{CO}_{2}$ assimilation in illuminated leaves of Brassica napus. New Phytol 185:988-999

Gnoni GV, Priore P, Geelen MJ, Siculella L (2009) The mitochondrial citrate carrier: metabolic role and regulation of its activity and expression. IUBMB Life 61:987-994

Haag-Kerwer A, Grams TFE, Olivares E, Ball E, Arndt S, Popp M, Medina E, Lüttge U (1996) Comparative measurements of gas exchange, acid accumulation and chlorophyll $a$ fluorescence of different species of Clusia showing $\mathrm{C}_{3}$ photosynthesis, or crassulacean acid metabolism, at the same site in Venezuela. New Phytol 134:215-226

Hanning I, Heldt HW (1993) On the function of mitochondrial metabolism during photosynthesis in spinach leaves (Spinacia oleracea L.). Partitioning between respiration and export of redox equivalents and precursors for nitrate assimilation products. Plant Physiol 103:1147-1154
Herppich M, Herppich WB, von Willert DJ (1995) Diurnal rhythm in citric acid content preceded the onset of nighttime malic acid accumulation during metabolic changes from $\mathrm{C}_{3}$ to CAM in saltstressed plants of Mesembryanthemum crystallinum. J Plant Physiol 147:38-42

Holtum JAM, Winter K (1982) Activity of enzymes of carbon metabolism during the induction of crassulacean acid metabolism in Mesembryanthemum crystallinum L. Planta 155:8-16

Igamberdiev AU, Gardeström P (2003) Regulation of NAD- and NADP-dependent isocitrate dehydrogenases by reduction levels of pyridine nucleotides in mitochondria and cytosol of pea leaves. Biochim Biophys Acta 1606:117-125

Kalt W, Osmond CB, Siedow JN (1990) Malate metabolism in the dark after ${ }^{13} \mathrm{CO}_{2}$ fixation in the crassulacean plant Kalanchoë tubiflora. Plant Physiol 94:826-832

Kenyon WH, Severson RF, Black CC Jr (1985) Maintenance carbon cycle in crassulacean acid metabolism plant leaves: source and compartmentation of carbon for nocturnal malate synthesis. Plant Physiol 77:183-189

Kornas A, Fischer-Schliebs E, Lüttge U, Miszalski Z (2009) Adaptation of the obligate CAM plant Clusia alata to light stress: metabolic responses. J Plant Physiol 166:1914-1922

Leterrier M, Del Rio LA, Corpas FJ (2007) Cytosolic NADPisocitrate dehydrogenase of pea plants: genomic clone characterization and functional analysis under abiotic stress conditions. Free Radic Res 41:191-199

Lüttge U (1988) Day-night changes of citric acid levels in CAM: phenomenon and ecophysiological significance. Plant Cell Environ 11:445-451

Maxwell C, Griffiths H, Young AJ (1994) Photosynthetic acclimation to light regime and water-stress by the $\mathrm{C}_{3}$-CAM epiphyte Guzmania monostachia: gas exchange characteristics, photochemical efficiency and the xanthophyll cycle. Funct Ecol 8:746-754

McIntosh CA, Oliver DJ (1992) Isolation and characterization of the tricarboxylate transporter from pea mitochondria. Plant Physiol 100:2030-2034

Miszalski Z, Ślesak I, Niewiadomska E, Baczek-Kwinta R, Lüttge U, Ratajczak R (1998) Subcellular localization and stress response of superoxide dismutase isoforms from leaves in the $\mathrm{C}_{3}$-CAM intermediate halophyte Mesembryanthemum crystallinum L. Plant Cell Environ 21:169-179

Miszalski Z, Niewiadomska E, Ślesak I, Kluge M, Ratajczak R (2001) The effect of irradiance on carboxylating/decarboxylating enzymes and fumarase activities in Mesembryanthemum crystallinum L. exposed to salinity stress. Plant Biol 3:17-23

Miszalski Z, Kornas A, Gawronska K, Ślesak I, Niewiadomska E, Kruk J et al (2007) Ecophysiological aspects of mitochondrial MnSOD activity in species of Clusia with obligate $\mathrm{C}_{3}$-photosynthesis and $\mathrm{C}_{3} / \mathrm{CAM}$ intermediate behaviour. Biol Plant 51:86-92

Neuhaus HE, Schulte N (1996) Starch degradation in chloroplasts isolated from $\mathrm{C}_{3}$ or CAM (crassulacean acid metabolism)induced Mesembryanthemum crystallinum L. Biochem J 318:945-953

Niewiadomska E, Borland AM (2008) Crassulacean acid metabolism: a cause or consequence of oxidative stress in planta? In: Lüttge U, Beyschlag W, Murata J (eds) Progress in botany 69. Springer, Verlag, pp 247-266

Niewiadomska E, Bilger W, Gruca M, Mulisch M, Miszalski Z, Krupinska K (2011) CAM-related changes in chloroplastic metabolism of Mesembryanthemum crystallinum L. Planta 233:275-285

Noguchi K, Yoshida K (2008) Interaction between photosynthesis and respiration in illuminated leaves. Mitochondrion 8:87-99 
Osmond CB (1978) Crassulacean acid metabolism: a curiosity in context. Annu Rev Plant Physiol 29:379-414

Osmond CB, Holtum JAM, O'Leary MH, Roeske C, Wong OC, Summons RE, Avadhani PNC (1988) Regulation of malic-acid metabolism in crassulacean-acid-metabolism plants in the dark and light: in vivo evidence from ${ }^{13} \mathrm{C}$-labelling patterns after ${ }^{13} \mathrm{CO}_{2}$ fixation. Planta 175:184-192

Palmieri L, Picault N, Arrigoni R, Besin E, Palmieri F, Hodges M (2008) Molecular identification of three Arabidopsis thaliana mitochondrial dicarboxylate carrier isoforms: organ distribution, bacterial expression, reconstitution into liposomes and functional characterization. Biochem J 410:621-629

Peckmann K, Herppich WB (1998) Effects of short-term drought and rewatering on the activity of mitochondrial enzymes and the oxidative capacity of leaf mitochondria from a CAM plant, Aptenia cordifolia. J Plant Physiol 152:518-524

Picault N, Hodges M, Palmieri L, Palmieri F (2004) The growing family of mitochondrial carriers in Arabidopsis. Trends Plant Sci 9:138-146

Popova OV, Ismailov SF, Popova TN, Dietz JJ, Golldack D (2002) Salt-induced expression of NADP-dependent isocitrate dehydrogenase and ferredoxin-dependent glutamate synthese in Mesembryanthemum crystallinum. Planta 215:906-913

Racker E (1950) Spectrophotometric measurement of the enzymatic formation of fumaric and cis aconitic acids. Biochim Biophys Acta 4:211-214

Srere PA (1967) Citrate synthase. Methods Enzymol 13:3-11
Sweetlove LJ, Beard KFM, Nunes-Nesi A, Fernie AR, Ratcliffe RG (2010) Not just a circle: flux modes in the plant TCA cycle. Trends Plant Sci 15:462-470

Tcherkez G, Mahé A, Gauthier P, Mauve C, Gout E, Bligny R, Cornic G, Hodges M (2009) In folio respiratory fluxomics revealed by ${ }^{13} \mathrm{C}$ isotopic labeling and $\mathrm{H} / \mathrm{D}$ isotope effects highlight the noncyclic nature of the tricarboxylic acid 'cycle' in illuminated leaves. Plant Physiol 151:620-630

Verbruggen N, Hua XJ, May M, Van Montagu M (1996) Environmental and developmental signals modulate proline homeostasis: evidence for a negative transcriptional regulator. Proc Natl Acad Sci USA 93:8787-8791

Winter K, Smith JAC (1996) Crassulacean acid metabolism: current status and perspectives. In: Winter K, Smith JAC (eds) Crassulacean acid metabolism biochemistry, ecophysiology and evolution. Springer, Berlin, pp 389-426

Winter K, Foster JG, Edwards GE, Holtum JAM (1982) Intracellular localization of enzymes of carbon metabolism in Mesembryanthemum crystallinum exhibiting $\mathrm{C}_{3}$ photosynthetic characteristics or performing crassulacean acid metabolism. Plant Physiol 69:300-307

Wiskich JT, Dry IB (1985) The tricarboxylic acid cycle in plant mitochondria: its operation and regulation. In: Douce R, Day DA (eds) Encyclopedia of plant physiology, higher plant cell respiration, vol 18. Springer, Berlin, pp 281-313 